\title{
Synthesis and characterization of hierarchical titanium-containing silicas using different size templates
}

\author{
ALEKSEY FEDOSOV ${ }^{\mathrm{a}}$, MARINA FEDOSOVA ${ }^{\mathrm{a}}$, IRINA POSTNIKOVA ${ }^{\mathrm{a}}$, SERGEY OREKHOV ${ }^{\mathrm{a}}$, \\ ALEKSEY GUSHCHIN ${ }^{\mathrm{b}}$, DENIS RYABININ ${ }^{\mathrm{c}}$ and ILYA CHUZHAYKIN ${ }^{\mathrm{a}, \mathrm{b}, *}$ \\ ${ }^{a}$ Nizhny Novgorod State Technical University n.a. R.E. Alekseev, 49, Gaidar Street, Dzerzhinsk, \\ Nizhny Novgorod Region, Russia 606026 \\ ${ }^{b}$ Lobachevsky State University of Nizhny Novgorod, National Research University, 23, Gagarin Avenue, \\ Nizhny Novgorod, Russia 603950 \\ ${ }^{\mathrm{c}}$ University of Alberta, 116 St. and 85 Ave., Edmonton, AB, Canada \\ E-mail: chujaikin@yandex.ru
}

MS received 7 February 2019; revised 25 April 2019; accepted 26 May 2019

\begin{abstract}
The development of hierarchical catalytic heterogeneous catalytic systems with a controlled micro/mesopore ratio is an important issue in catalysis. The main purpose of the paper is to the establish influence of the size of the template molecule on the main characteristics of hierarchical titanium-containing silicas (H-TS). The H-TS were successfully synthesized by a bi-template method using tetrapropylammonium hydroxide (TPAG) as permanent template of MFI topology and tetramethylammonium bromide (TMAB), tetraethylammonium bromide (TEAB), tetrabutylammonium hydroxide (TBAG), dodecyltrimethylammonium bromide (DTMAB), cetyltrimethylammonium bromide (CTAB), didecyldimethylammonium chloride (DDAC), tetradecylbenzyldimethylammonium bromide (TBDAB) as variable structure-directing agent (SDA) of a different size. The structure and morphology were characterized by X-ray diffraction, a Fourier transform infrared spectroscopy, a Raman spectroscopy, a scanning electron microscopy and low-temperature nitrogen adsorption-desorption. The catalytic properties of the prepared titanium-containing micro-mesoporous silicas for hydroxylation of phenol with $\mathrm{H}_{2} \mathrm{O}_{2}$ have been evaluated, and their activities have been compared with those of TS-1 with only micropores. The findings of the research illustrate that with an increase in the molecule volume of the structure-directing agent, there is a decrease in the proportion of the crystalline phase and in the degree of the inclusion of $\mathrm{Ti}^{4+}$ atoms in the structure of the zeolite material. Increase in the volume of the structure-directing agent leads to the decrease of the crystallinity of the samples and decrease in the specific surface area of the material and in the specific volume of micropores. The result of this research will be used to create a theoretical model of controlled micro-/mesoporous ratio in silicas and it may open new perspectives for their potential application in selective oxidation reactions involving large molecules.
\end{abstract}

Keywords. Hierarchical silica; titanium silicalite; bi-template synthesis; mixed templates.

\section{Introduction}

Selective oxidation of organic compounds into targeted products using 'green' oxidizing agents is a priority for catalysis. Despite numerous achievements and discoveries in the area of oxidation processes, unsustainable methods for producing oxygenated compounds still persist in the industry. Generally, manufacturers rely on acids and soluble metal complexes as catalysts for their processes, both of which involve increased energetic and economic costs for their isolation and recovery processes, as well as the formation of significant amounts of waste. ${ }^{1}$ The lack of universally heterogeneous catalyst systems, being of considering steric, and other factors is the main reason for the complete abandonment of the use of homogeneous catalysts. ${ }^{2}$

\footnotetext{
*For correspondence

Electronic supplementary material: The online version of this article (https://doi.org/10.1007/s12039-019-1652-3) contains supplementary material, which is available to authorized users.
} 
Zeolite materials are the most relevant catalytic systems in the field of oxidation of organic compounds. Zeolites are crystalline substances with a developed internal system of pores and channels, which are regularly repeated in three-dimensional space. ${ }^{3}$ The availability and variety of the primary components needed for the synthesis of zeolite materials makes it possible to obtain materials with the necessary properties and structure. $^{4}$

A genuine breakthrough in the field of liquid-phase oxidation was made by a microporous titanium silicalite (TS-1), developed by the company Enichem in 1986. Due to the titanium centers in its structure, this catalyst allows selectively and under mild conditions to oxidize secondary alcohols into ketones, ${ }^{5}$ alkanes into alcohols, ${ }^{6}$ epoxidation alkenes and unsaturated acids, ${ }^{7,8}$ etc., using an 'environment-friendly' hydrogen peroxide oxidizer. However, the use of TS-1 is severely limited due to its microporosity and is only suitable for substrates with a kinetic size of up to $6 \AA$ (linear alkanes and olefins). Therefore, the problem of selective oxidation of large organic molecules remains. Thereby, the creation of catalysts with an extensive network of pores is required.

An attempt to solve this problem was made in the 1990s by developing mesoporous catalytic systems based on materials MCM-41 and MCM-48 containing titanium atoms and other transition metals in the crystalline structure. ${ }^{10,11}$ Despite the significant advantage of the diffusion of large molecules in mesoporous silicate materials, their catalytic activity is lower than that of microporous ones. ${ }^{12}$ Therefore, in the last fifteen years, there has been increased development in the synthesis methods of zeolite materials with a hierarchical structure, which apart from micropores also have an additional material treatment system formed by meso and/or macropores.

The most common method for creating large pores in zeolite materials consists of the partial destruction of the structure. However, such a method leads to a chaotic formation of pores of uncontrolled size a significant material loss. ${ }^{13-18}$

An innovative solution is the direct template synthesis of catalyst systems. ${ }^{19-23}$ The use of various structure directing agents at the stage of synthesis of zeolite material followed by removal through ignition makes it possible to achieve a uniform and controlled distribution of pores which is vital for diffusing processes occurring in the catalyst grain.

In this work, we prepared hierarchical titaniumcontaining silicas with micro-mesoporous structure by the dual-templating method. We used the SDA different size for regulation micro-, mesoporous ratio. The catalytic activity of the materials in the hydroxylation of phenol is reported and compared with that of a conventional TS-1 sample.

\section{Experimental}

\subsection{Materials}

The chemicals and reagents used for the synthesis were obtained from commercial sources. Tetrapropylammonium hydroxide (TPAOH) $\left(1 \mathrm{M}\right.$ in $\left.\mathrm{H}_{2} \mathrm{O}\right)$, tetramethylammonium bromide (TMAB) (98\%), tetraethylammonium bromide (TEAB) $(98 \%)$, tetrabutylammonium hydroxide $(\mathrm{TBAOH})$ (40\% wt. in $\mathrm{H}_{2} \mathrm{O}$ ), dodecyl trimethylammonium bromide (DTMAB) (98\%), cetyltrimethylammonium bromide (CTAB) (98\%), titanium butoxide (TBOT) $(97 \%)$ were purchased from Merck. Didecyldimethylammonium chloride (DDAC) $(95 \%)$ was procured from Supelco. Tetradecylbenzyldimethylammonium bromide (TBDAB) $\left(50 \%\right.$ wt. in $\left.\mathrm{H}_{2} \mathrm{O}\right)$ was procured from Vecos. Tetraethoxysilane (TEOS) (99\%), phenol $(99 \%)$, hydrogen peroxide $(36.5 \%)$, titanium dioxide (anatase) (98\%) were procured from Vekton. All the chemicals were of analytical grade and were used as obtained without further purification.

\subsection{Synthesis of hierarchical titanium silicas}

Samples of the titanium-containing silicas were synthesized by the dual-templating method using mixed structuredirecting agents. We used two structure-directing agents, where TPAOH acted as a permanent structure-directing agent (SDA) and TMAB, TEAB, TBAOH, DTMAB, CTAB, DDAC, TBDAB as variable templates. The synthesis of micro-mesoporous titanium silicalites was carried out according to the following procedure. An exact amount of TEOS was loaded in a temperature-controlled glass reactor with a capacity of $100 \mathrm{~mL}$. The reactor was purged with nitrogen to create an inert atmosphere and, with stirring, an exact amount of TBOT was introduced. The resulting mixture was cooled to the temperature of about $1.0^{\circ} \mathrm{C}$. Then, with vigorous mixing, the calculated amounts of templates and deionized water were added. The final stoichiometric composition of micromesoporous titanium silicalites samples had the following form of $\mathrm{SiO}_{2}: 0.02 \mathrm{TiO}_{2}: 0.5 \mathrm{TPAG}: 0.5 \mathrm{X}: 50 \mathrm{H}_{2} \mathrm{O}$, where $\mathrm{X}=$ TMAB, TEAB, TBAOH, DTMAB, CTAB, DDAC, TBDAB. By comparison, the titanium silicalite was synthesized by the same method without a variable template; the silicalite- 1 was synthesized by the same method without TBOT and variable template.

The obtained gel-sol was subjected to hydrothermal treatment in a steel autoclave with a volume of $250 \mathrm{~mL}$ at $170^{\circ} \mathrm{C}$ for $50 \mathrm{~h}$.

The crystallized titanium silicalite was separated from the mother liquor, washed with deionized water to neutral $\mathrm{pH}$ and dried at $120^{\circ} \mathrm{C}$ and the residual pressure of 
40-60 $\mathrm{mm} \mathrm{Hg}$, and then calcinated in the air for $6 \mathrm{~h}$ at $550{ }^{\circ} \mathrm{C}$.

\subsection{Characterization of the samples}

Fourier-transform infrared (FTIR) spectra were recorded in the $400-4000 \mathrm{~cm}^{-1}$ range on an FTIR spectrometer Shimadzu IRAffinity-1 using the $\mathrm{KBr}$ pellet technique. X-ray diffraction (XRD) patterns were recorded on a Shimadzu $\mathrm{XRD}-7000$ with $\mathrm{Cu}-\mathrm{K} \alpha$ radiation $(40 \mathrm{kV}, 50 \mathrm{~mA})$ in the range 2 teta of $6^{\circ}$ and $50^{\circ}$ with the angular step size of $0.02^{\circ}$.

The specific surface area and volume pore of the samples were determined by nitrogen adsorption-desorption measurements at $77 \mathrm{~K}$ on the nitrogen adsorption apparatus Sorbi-MS. Before the measurements, the samples were outgassed at $110^{\circ} \mathrm{C}$ in vacuum for $1 \mathrm{~h}$. The specific surface area was calculated using method Brunauer-Emmett-Teller (BET). The volume of the micropores and the surface of the mesopores were determined by the Bour-Lippens (STSA) method.

The scanning electron microscopy (SEM) was performed on the scanning electron microscope JEOL JSM-IT300LV with an accelerating voltage of $20 \mathrm{kV}$.

Raman spectra were recorded by using a NTEGRA Spectra instrument equipped with laser line $473 \mathrm{~nm}$. Laser power was kept at $3.6 \mathrm{~mW}$.

For calculating molecule volume, there was used a method developed at Molinspiration. ${ }^{24}$

\subsection{Hydroxylation of phenol}

The liquid-phase catalytic reaction was performed in a 50 $\mathrm{mL}$ two-necked glass reactor fitted with a water condenser at $60^{\circ} \mathrm{C}$ under vigorous stirring. A typical reaction involves $2.4 \mathrm{mmol}$ of the substrate, $0.8 \mathrm{mmol}$ of $\mathrm{H}_{2} \mathrm{O}_{2}, 38.0 \mathrm{~mL} \mathrm{H}_{2} \mathrm{O}$ and $0.2050 \mathrm{~g}$ samples H-TS. The progress of the reaction was monitored by analyzing the products obtained at different intervals through the capillary gas chromatograph (Chromos GH-1000, VB-5 $30 \mathrm{~m}$ x $0.32 \mathrm{~mm}$ columns with flame ionization detector). The products were identified by GC-MS (Shimadzu GCMS-QP2020) splitting pattern. The concentration of residual $\mathrm{H}_{2} \mathrm{O}_{2}$ was determined by an iodometric titration with sodium thiosulphate $(0.1 \mathrm{~N})$ in the presence of starch as an indicator. The aliquot of the samples was withdrawn during the reaction and was quickly subjected to titration.

\section{Results and Discussion}

\subsection{Molecule volume}

The samples of micro-mesoporous titanium-containing silicate materials were obtained by the method of direct synthesis using structure-directing agents of various volume. The volume of the template molecule was
Table 1. The volume of the template molecule.

\begin{tabular}{lc}
\hline Template & Molecule volume $\left(\mathrm{nm}^{3}\right)$ \\
\hline TMAB & 0.0951 \\
TEAB & 0.1623 \\
TPAG & 0.2295 \\
TBAG & 0.2967 \\
DTMAB & 0.2799 \\
CTAB & 0.3471 \\
TBDAB & 0.3684 \\
DDAC & 0.3975 \\
\hline
\end{tabular}

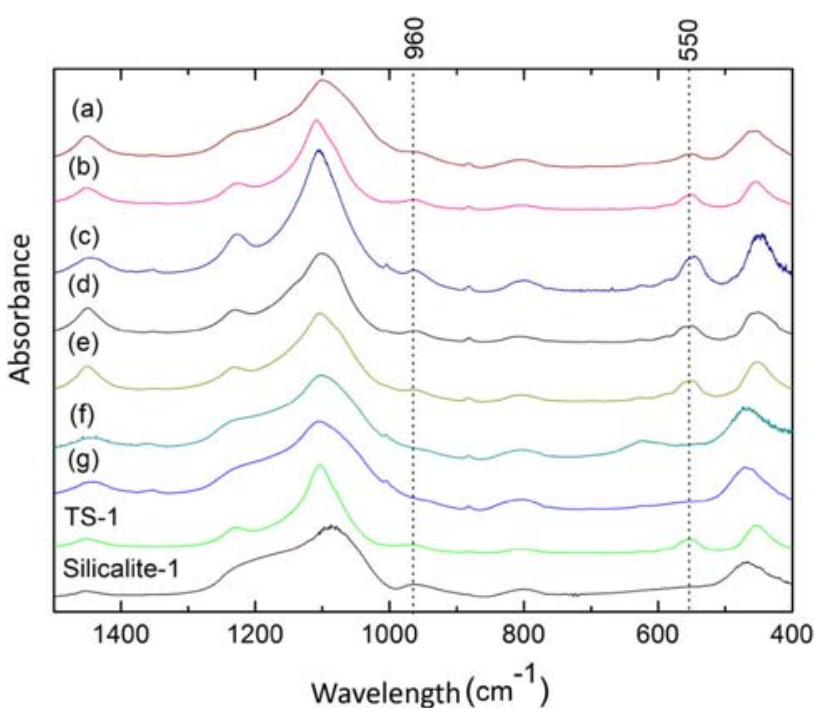

Figure 1. The fragment of the infrared spectrum of the samples. a - TMAB, b - TEAB, c - DTMAB, d -TBAOH, e CTAB, f - TBDAB, g - DDAC.

calculated using the program. ${ }^{24}$ The results of the calculation are shown in Table 1.

\subsection{FT-IR analysis}

In the infrared spectrum of the obtained materials, the absorption bands characteristic of titanium silicates are observed: $\nu_{\text {as }}(\mathrm{Si}-\mathrm{O}-\mathrm{Si})$ at $1040-1080 \mathrm{~cm}^{-1}$, $\nu(\mathrm{Si}-\mathrm{O}-\mathrm{Ti})$ and $\delta(\mathrm{Si}-\mathrm{O}-\mathrm{Ti})$ at $960-980 \mathrm{~cm}^{-1}, \mathrm{v}_{\mathrm{s}}(\mathrm{Si}-$ $\mathrm{O}-\mathrm{Si})$ at $810 \mathrm{~cm}^{-1}$ and $\delta(\mathrm{Si}-\mathrm{O}-\mathrm{Si})$ at $435 \mathrm{~cm}^{-1}$, (Si$\mathrm{O}-\mathrm{Ti})$ and $(\mathrm{Si}-\mathrm{O}-\mathrm{Si})$ at $540-550 \mathrm{~cm}^{-1} \cdot{ }^{25}$ For a rough estimate of the feeding rate of $\mathrm{Ti}^{4+}$ atoms in the framework of zeolite material, the ratio of the peak intensities at $960 \mathrm{~cm}^{-1}$ and $550 \mathrm{~cm}^{-1}$ (I960/I550) was used. Figure 1 shows the infrared spectrum of the obtained samples.

Figure 2 shows the graph of the inclusion of $\mathrm{Ti}^{4+}$ ions in the frame samples. 


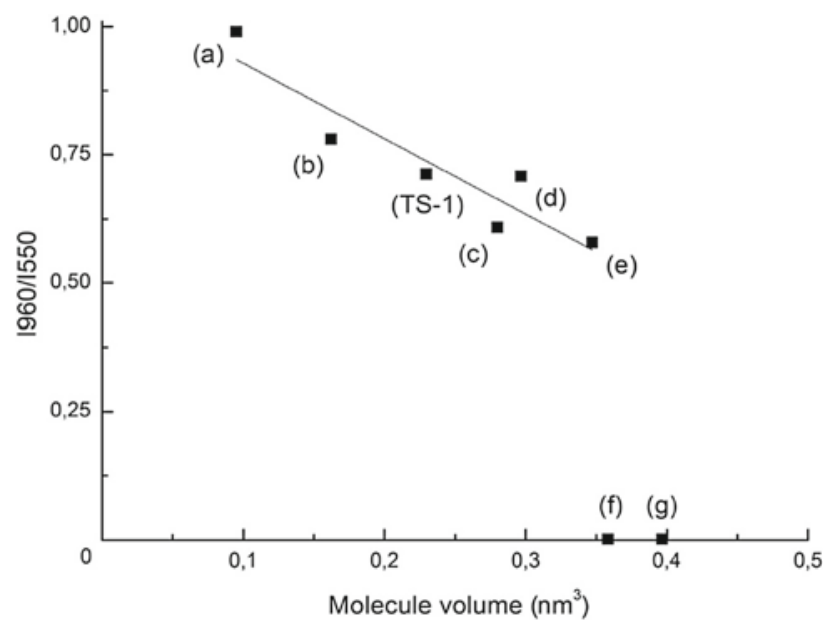

Figure 2. The graph of the inclusion of $\mathrm{Ti}^{4+}$ ions in samples according to the template molecule volume. a - TMAB, b TEAB, c - DTMAB, d -TBAOH, e - CTAB, f - TBDAB, $g$ - DDAC.

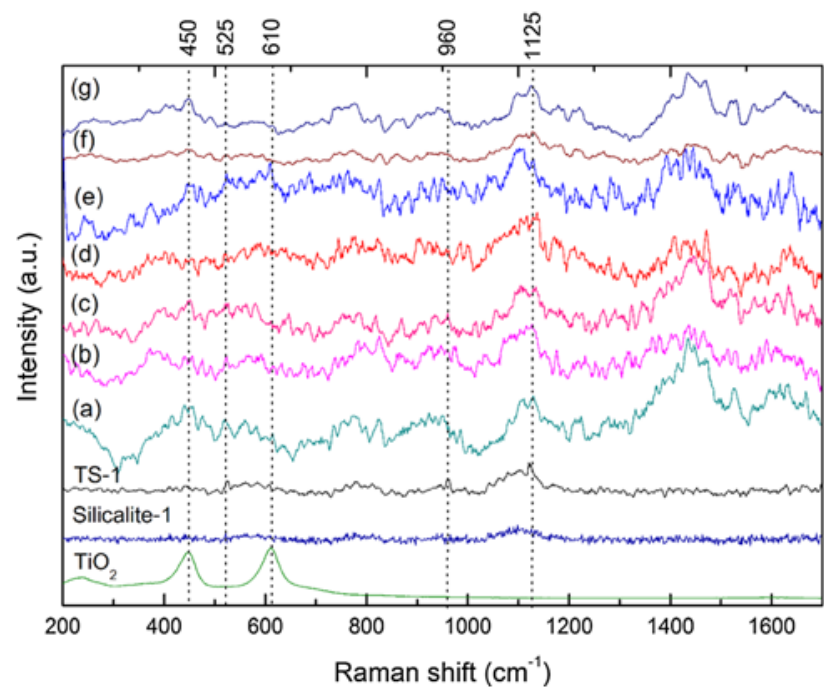

Figure 3. Raman spectra of samples H-TS (a-g), anatase $\left(\mathrm{TiO}_{2}\right)$, silicalite-1 and TS-1. a - TMAB, b - TEAB, c DTMAB, d -TBAOH, e - CTAB, f - TBDAB, g - DDAC.

It was found that an increase in the size of the template leads to a decrease in the degree of inclusion of $\mathrm{Ti}^{4+}$ ions. Probably, this dependence is due to the fact that when using a template with a small molecule size, a denser 'packing' of crystals occurs, leading to the fact that the structure contains more titanium atoms per unit volume, in contrast to crystals with mesopores.

\subsection{Raman spectroscopy}

Raman spectra of the samples H-TS are shown in Figure 3. The spectra of the H-TS samples were compared with anatase $\left(\mathrm{TiO}_{2}\right)$, silicalite- 1 and TS-1.

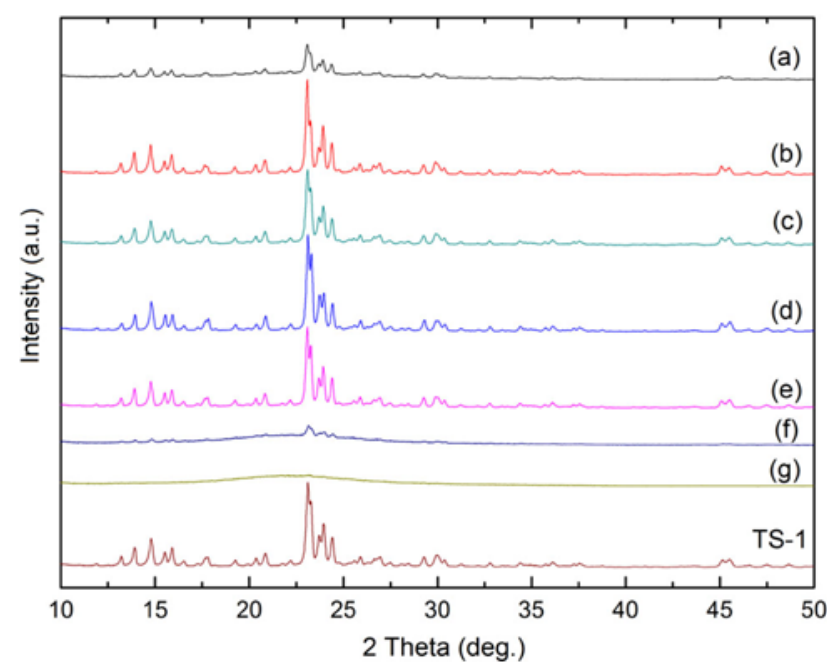

Figure 4. XRD pattern of samples $a-T M A B, b-T E A B$, c-DTMAB, d-TBAOH, e - CTAB, f - TBDAB, g-DDAC.

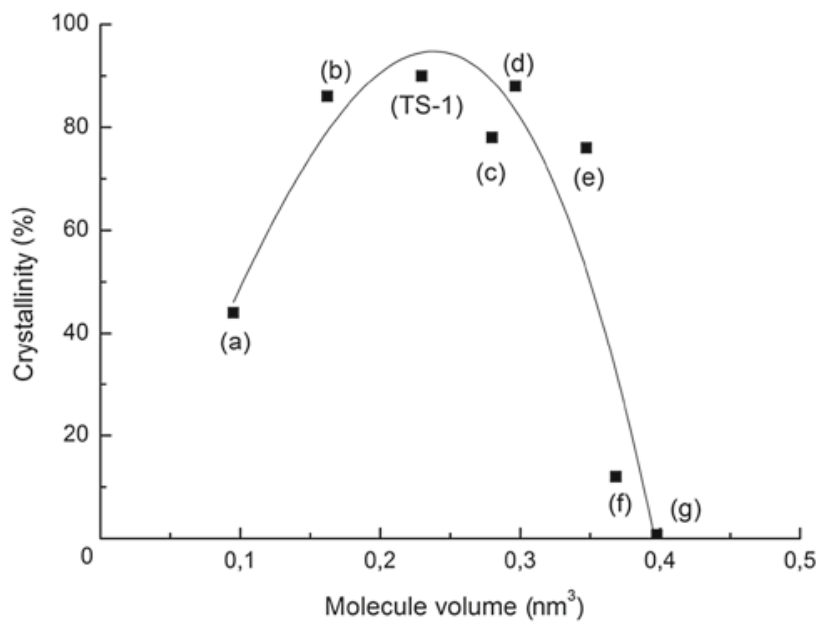

Figure 5. The graph of crystallinity on the template molecule volume. a - TMAB, b - TEAB, c - DTMAB, d -TBAOH, e - CTAB, f - TBDAB, g - DDAC.

The characteristic bands of $\mathrm{TiO}_{2}$ at $473 \mathrm{~nm}$ are 230, $450,610 \mathrm{~cm}^{-1}$. For TS-1, 525-530, 960, $1125 \mathrm{~cm}^{-1}$ are considered. These bands are associated with framework $\mathrm{Ti}$ and it doesn't attribute to silicalite- 1 . The first band $\left(525-530 \mathrm{~cm}^{-1}\right)$ assigned to the symmetric stretching vibration of framework Ti-O-Si species. Both the 960 and $1125 \mathrm{~cm}^{-1}$ bands attribute to the $\mathrm{Ti}^{4+}$ active sites of TS-1. ${ }^{26-28}$

From the data obtained it could be concluded that samples (a-e) contain titanium in the form of isolated atoms in the crystal structure of the silicalite material with small amounts of anatase. In the samples with TBDAB and DDAC templates is predominantly in the form of $\mathrm{TiO}_{2}$, as indicated by the absence of absorption bands at 960 and $1125 \mathrm{~cm}^{-1}$. 
Table 2. Textural data of the samples.

\begin{tabular}{lcccc}
\hline Samples & Second template & $\mathrm{S}_{\text {BET }}\left(\mathrm{m}^{2} / \mathrm{g}\right)$ & $\mathrm{V}_{\text {micro }}\left(\mathrm{cm}^{3} / \mathrm{g}\right)$ & $\mathrm{S}_{\text {meso }}\left(\mathrm{m}^{2} / \mathrm{g}\right)$ \\
\hline TS-1 & - & 349.5 & 0.156 & 9.1 \\
$\mathrm{a}$ & TMAB & 171.7 & 0.072 & 13.7 \\
$\mathrm{~b}$ & TEAB & 338.5 & 0.136 & 47.1 \\
$\mathrm{c}$ & DTAB & 289.2 & 0.106 & 58.5 \\
$\mathrm{~d}$ & TBAG & 319.2 & 0.145 & 6.0 \\
$\mathrm{e}$ & CTAB & 264.3 & 0.105 & 34.0 \\
$\mathrm{f}$ & TBDAB & 120.3 & 0.026 & 61.3 \\
$\mathrm{~g}$ & DDAC & 102.9 & 0.004 & 92.7 \\
\hline
\end{tabular}

\subsection{XRD analysis}

Figure 4 illustrates the powder XRD patterns of samples. The MFI (TS-1) crystal structure appears on the radiograph in the form of several intense peaks in the region of the average angles $2 \theta=7$ to $50^{\circ}$, which characterize the crystal structure of the orthorhombic unit cell TS- $1 .^{29}$

The sorted peaks of the samples (a) and (f) (Figure 4) have a low intensity which indicates low crystallinity of the structure, and in the case of the sample (g), full amorphousness of material is observed.

We can see that the nature of the spectrum of sample 2 in the region $2 \theta=45^{\circ}-45.5^{\circ}$ is slightly different from the others. The presence of a more intense peak of $2 \theta=45^{\circ}$ in the $45.0^{\circ}$ and $45.5^{\circ}$ doublet indicates the presence of an orthorhombic crystal structure MEL. It was found that in sample (b) there are two types of crystal structures MFI and MEL with the phase ratio MEL/MFI of 40.9/59.1. Only the MFI crystal structure was found in the other samples.

Figure 5 indicates the dependency of crystallinity on the template molecule volume. It was found that with an increase of the volume of the template, the fraction of the crystal phase in the samples decreases. The use of TMAB led to the formation of a structure with low crystallinity and probably the use of this structure-forming component affects the method of particle aggregation during crystal growth.

\subsection{Textural properties}

The combination of meso- and microporosity was proven by nitrogen adsorption-desorption. Textural properties are summarized in Table 2.

It has been discovered that with an increase of the volume of the structure-directing agent molecule, the specific surface area of the material, as well as the specific volume of micropores, decrease. This is explained by the fact that large molecules of the template form larger mesopores, which leads to a decrease in the total surface area due to the presence of voids. Confirming this theory, the surface area of mesopores naturally increases. However, the use of tetramethylammonium ion as a template leads to the formation of a nonporous or supermicroporous system due to poor coordination of the template and precursors of silicon and titanium.

Figure 6 indicates two types of pore size distributions. Samples (a), (b), (e), (f) and (g) there are wide distribution of pores without prevailing pore size. Samples (c) and (d) show the relatively narrow distribution of pores with peaks centered on $27 \mathrm{~nm}, 141 \mathrm{~nm}$ (c) and $41 \mathrm{~nm}$, $140 \mathrm{~nm}(\mathrm{~d})$.

\subsection{Morphology study by SEM}

The SEM images in Figure 7 are consistent with the XRD data discussed above.

SEM images depict a change in the shape of crystals of H-TS samples with varying templates. It can be concluded that the increase in the size of SDA sterically hinders the uniform growth of a symmetric crystal, which leads to the formation of structures with a chaotic size and the decrease in crystallinity.

\subsection{Catalytic test}

Table 3 presents the results of the catalytic performance of the synthesized H-TS using $\mathrm{H}_{2} \mathrm{O}_{2}$ as the oxidant in the hydroxylation of phenol.

Among the synthesized H-TS materials, sample (c) shows the highest performance in the hydroxylation of phenol reaction due to the optimal volume of the mesopore and relatively high crystallinity. The substrate conversions are $10,93 \%$ and dihydroxybenzene (hydroquinone (HQ) and catechol (CAT)) selectivity are $59,57 \%$ which are larger than those other samples H-TS and TS-1. 

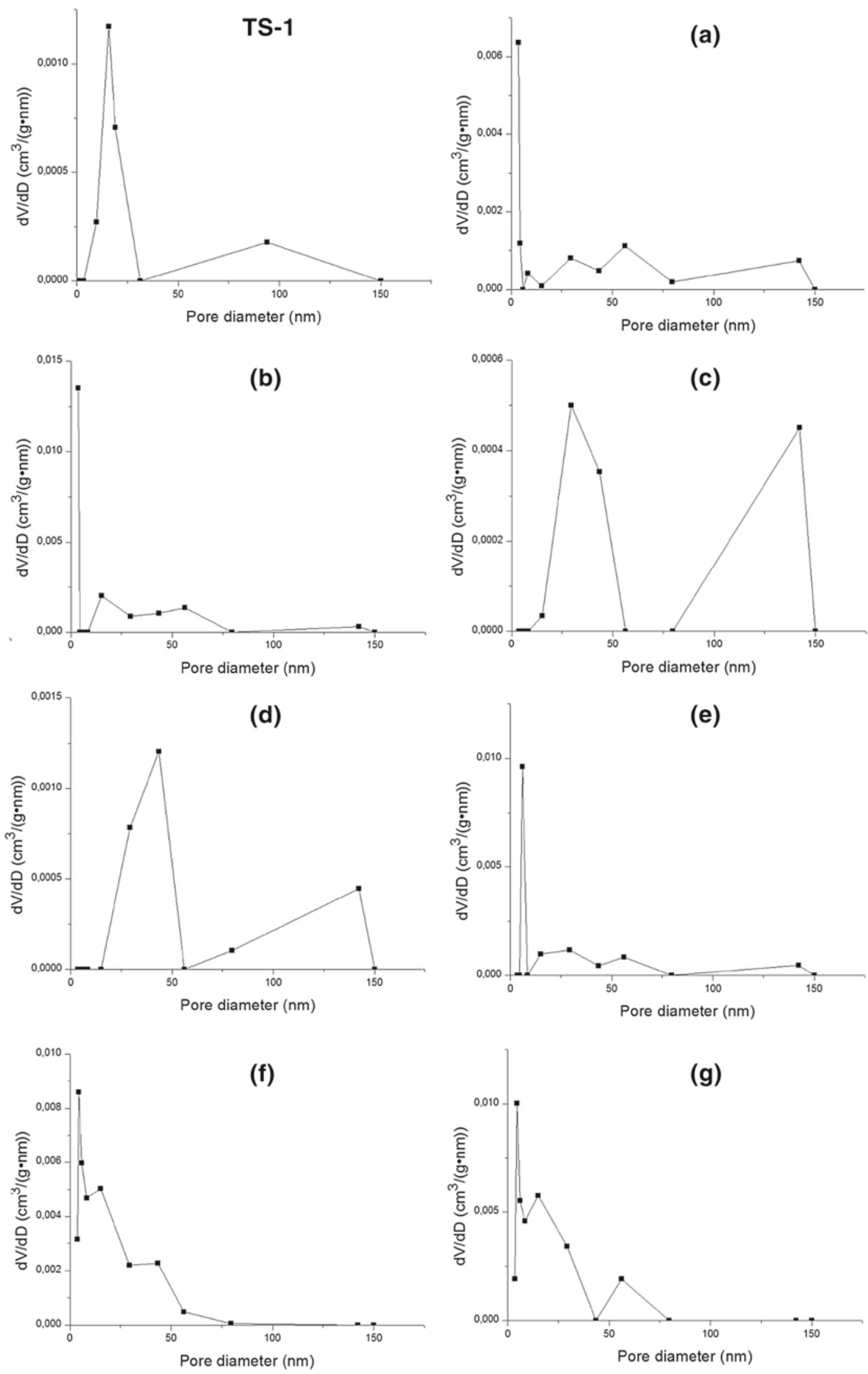

Figure 6. The graph of pore distribution in the samples a - TMAB, b-TEAB, c - DTMAB, $d$ -TBAOH, e - CTAB, f - TBDAB, g- DDAC. 
(a)

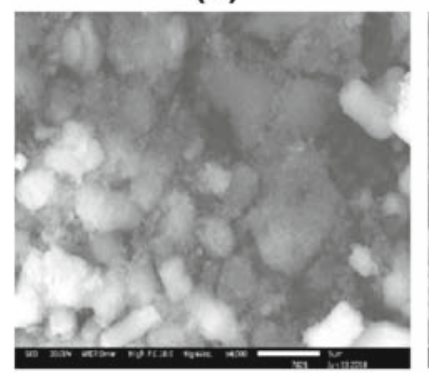

(c)

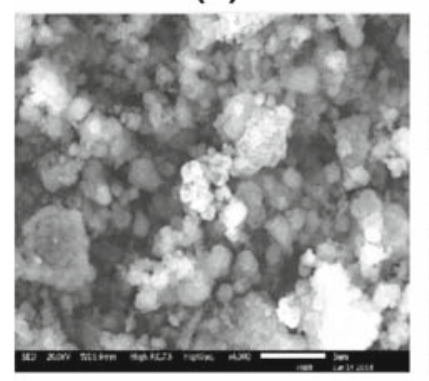

(e)

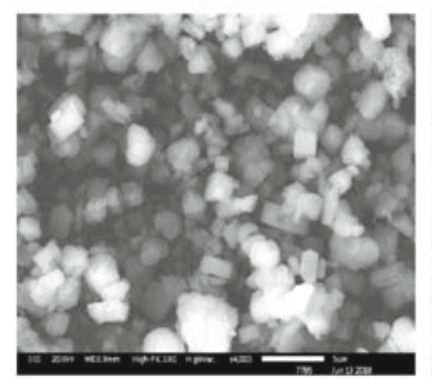

(g)

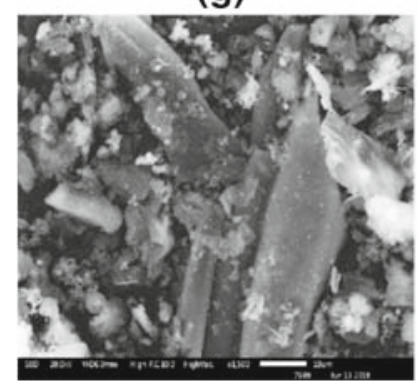

Figure 7. SEM image of samples a - TMAB, b-TEAB, c - DTMAB, d -TBAOH, e - CTAB, f - TBDAB, g - DDAC.

(b)

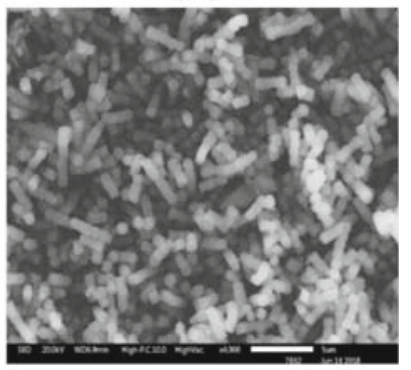

(d)

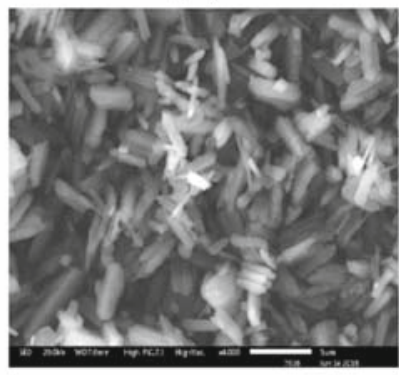

(f)

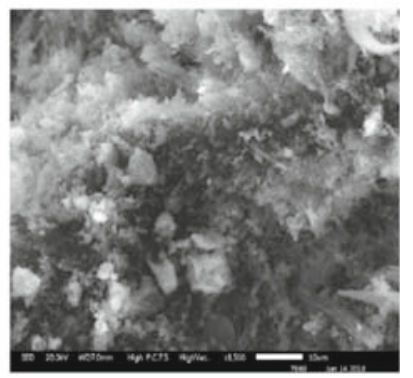

TS-1

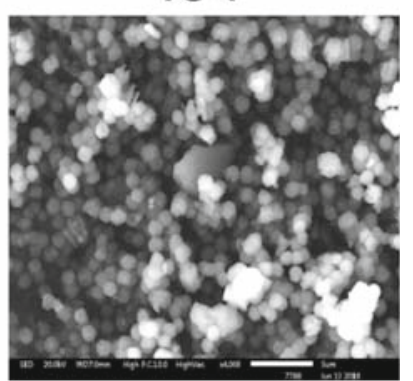

\section{Supplementary Information (SI)}

All additional information related to characterization H-TS using FT-IR (Figure S1, Figure S2), XRD pattern (Figure S3, Figure S4), SEM (Figure S5) are given in the supplementary information available at www.ias.ac.in/chemsci.

Table 3. Phenol hydroxylation of over various catalysts.

\begin{tabular}{lccccc}
\hline Samples & Second template & Conv. phenol (\%) & \multicolumn{3}{c}{ Product selectivity $(\%)$} \\
\cline { 4 - 6 } & & & HQ & CAT & BQ \\
\hline TS-1 & - & 10.65 & 34.06 & 29.89 & 5.10 \\
a & TMAB & 3.64 & 0.08 & 2.04 & 5.89 \\
b & TEAB & 8.95 & 14.58 & 20.69 & 13.04 \\
c & DTAB & 10.93 & 17.05 & 29.22 & 13.30 \\
d & TBAG & 9.93 & 12.33 & 21.43 & 14.05 \\
e & CTAB & 4.74 & 2.65 & 20.79 & 21.32 \\
f & TBDAB & 2.22 & 0.06 & 0.75 & 2.70 \\
g & DDAC & 1.16 & 1.16 & 1.28 & 3.88 \\
\hline
\end{tabular}




\section{Acknowledgements}

The study was financially supported by The Ministry of Education and Science of the Russian Federation (State assignment No. 10.2326.2017/PP).

The SEM study was carried out on the equipment of the Collective Usage Center "New Materials and Resource-saving Technologies" (Lobachevsky State University of Nizhny Novgorod).

The Raman spectroscopy was carried out in the Laboratory of Functional Nanomaterials (Lobachevsky State University of Nizhny Novgorod).

\section{References}

1. Clark J H and Rhodes C N 2000 In Clean Synthesis Using Porous Inorganic Solid Catalysts and Supported Reagents C N Rhodes (Ed.) (Cambridge: The Royal Society of Chemistry) p. 115

2. Centi G, Cavani F and Trifirò F 2001 In Selective Oxidation by Heterogeneous Catalysis. Fundamental and Applied Catalysis M V Twigg and M S Spencer (Eds.) (Boston: Springer) p. 505

3. Cubillas P and Anderson M W 2010 Synthesis Mechanism: Crystal Growth and Nucleation. In: Zeolites and Catalysis Synthesis, Reactions and Applications Vol.1 J Cejka (Ed.) (Weinheim: WILEY-VCH Verlag GmbH \& Co.) p. 56

4. J Cejka and H Bekkum (Eds.) 2005 Zeolites and Ordered Mesoporous Materials: Progress and Prospects G Centi (Series Ed.) (Prague: Gulf Professional Publishing)

5. Maspero F and Romano U 1994 Oxidation of Alcohols with $\mathrm{H}_{2} \mathrm{O}_{2}$ Catalyzed by Titanium Silicalite- $1 J$. Catal. 146476

6. Shulpin G B, Sooknoi T, Romakh V B, Süss-Fink G and Shulpina L S 2006 Regioselective Alkane Oxygenation with $\mathrm{H}_{2} \mathrm{O}_{2}$ Catalyzed by Titanosilicalite TS-1 Tetrahedron Lett. 473071

7. Lin M, Xia C, Zhua B, Li H and Shu X 2016 Green and efficient epoxidation of propylene with hydrogen peroxide (HPPO process) catalyzed by hollow TS- 1 zeolite: A $1.0 \mathrm{kt} / \mathrm{a}$ pilot-scale study Chem. Eng. J. 295370

8. Wilde N, Worch C, Suprun W and Gläser R 2012 Epoxidation of biodiesel with hydrogen peroxide over Ti-containing silicate catalysts Micropor. Mesopor. Mater. 164182

9. Kholdeeva O A and Trukhan N N 2006 Mesoporous titanium silicates as catalysts for the liquid-phase selective oxidation of organic compounds Russ. Chem. Rev. 75 460

10. Corma A, Blasco T, Navarro M T and Pariente J P 1995 Synthesis, Characterization, and Catalytic Activity of TiMCM-41 Structures J. Catal. 15665

11. Zhang W and Pinnavaia T J 1996 Transition metal substituted derivatives of cubic MCM-48 mesoporous molecular sieves Catal. Lett. 38261

12. Serrano D P, Escola J M and Pizarro P 2013 Synthesis strategies in the search for hierarchical zeolites Chem. Soc. Rev. $\mathbf{4 2} 4004$
13. Yu W, Deng L, Yuan P, Liu D, Yuan W and Chen F 2015 Preparation of hierarchically porous diatomite/MFI-type zeolite composites and their performance for benzene adsorption: The effects of desilication Chem. Eng. J. 270 450

14. Werner A, Bludovsky P, Selzer C, Koch U, Giebeler L, Oswald S and Kaskel S 2017 Hierarchical Ti-Beta Obtained by Simultaneous Desilication and Titanation as an Efficient Catalyst for Cyclooctene Epoxidation ChemCatChem. 93860

15. Verboekend D, Groen J C and Pérez-Ramírez J 2010 Interplay of Properties and Functions upon Introduction of Mesoporosity in ITQ-4 Zeolite Adv. Funct. Mater. 20 1441

16. Abello S, Bonilla A and Perez-Ramırez J 2009 Mesoporous ZSM- 5 zeolite catalysts prepared by desilication with organic hydroxides and comparison with $\mathrm{NaOH}$ leaching Appl. Catal. A 364191

17. Verboekend D, Vilé G and Pérez-Ramírez J 2012 Hierarchical Y and USY Zeolites Designed by Post-Synthetic Strategies Adv. Funct. Mater. 22916

18. Verboekend D, Mitchell S, Milina M, Groen J C and Pérez-Ramírez J 2011 Full Compositional Flexibility in the Preparation of Mesoporous MFI Zeolites by Desilication J. Phys. Chem. 11514193

19. Du Q, Guo Y, Duan H, Li H, Chen Y and Liu H 2017 Synthesis of hierarchical TS-1 zeolite via a novel three-step crystallization method and its excellent catalytic performance in oxidative desulfurization Fuel $\mathbf{1 8 8}$ 232

20. Du S, Sun Q, Wang N, Chen X, Jia M and Yu J 2017 Synthesis of hierarchical TS-1 zeolites with abundant and uniform intracrystalline mesopores and their highly efficient catalytic performance for oxidation desulfurization J. Mater. Chem. A 57992

21. Zuo Y, Zhang T, Liu M, Ji Y, Song C and Guo X 2018 Mesoporous/Microporous Titanium Silicalite with Controllable Pore Diameter for Cyclohexene Epoxidation Ind. Eng. Chem. Res. 57512

22. Rani P, Srivastava R and Satpati B 2016 One-Step Dual Template Mediated Synthesis of Nanocrystalline Zeolites of Different Framework Structures Cryst. Growth Des. 163323

23. Xing J, Jiang S, Pang J, Yuan E, Ma X, Lam K, Xue Q and Zhan K 2015 One-pot pseudomorphic crystallization of mesoporous porous silica to hierarchical porous zeolites Mater. Charact. 107161

24. Molinspiration. Calculation of Molecular Properties and Bioactivity Score https://www.molinspiration.com/ cgi-bin/properties (accessed on 20 February 2019)

25. Boccuti M R, Rao K M, Zecchina A, Leofanti G and Petrini G 1989 Spectroscopic Characterization of Silicalite and Titanium-Silicalite Stud. Surf. Sci. Catal. 48 133

26. Fan F, Feng Z and Li C 2010 UV Raman Spectroscopic Studies on Active Sites and Synthesis Mechanisms of Transition Metal-Containing Microporous and Mesoporous Materials Acc. Chem. Res. 43 378

27. Li C, Xiong G, Xin Q, Liu J, Ying P, Feng Z, Li J, Yang W, Wang Y and Wang G 1999 UV Resonance Raman Spectroscopic Identification of Titanium Atoms in the 
Framework of TS-1 Zeolite Angew. Chem. Int. Ed. 38 2220

28. Deo G, Turek A M, Wachs I E, Huybrechts D R and Jacobs P A 1993 Characterization of titania silicalites Zeolites 13365
29. Marra G L, Artioli G, Fitch A N, Milanesio M and Lamberti C 2000 Orthorhombic to monoclinic phase transition in high-Ti-loaded TS-1: an attempt to locate Ti in the MFI framework by low temperature XRD Micropor. Mesopor. Mater. 4085 